\title{
Research of the Relationship between Content and Ratio of Nitrogenous, Phosphate, Potash Fertilizer in Flue Cured Tobacco and Incidence of Tobacco Vein Spot Disease
}

\author{
Yingxia Guang \\ Kunming University, Kunming, Yunnan, 650214, China
}

\begin{abstract}
Keywords: Fertilization, Tobacco vein spot disease, Nitrogenous fertilizer, Phosphate fertilizer, Potash fertilizer, Relevance
\end{abstract}

\begin{abstract}
With time developing, tobacco vein spot disease is a very common and serious infectious disease in tobacco plants, and is one of the most serious diseases of tobacco in the world. Tobacco vein spot disease is becoming more and more epidemic outbreak around the world and has already attracted extensive attention. In this paper, the relationship between different content and ratio of nitrogenous $(\mathrm{N})$, phosphate $(\mathrm{P})$, potash $(\mathrm{K})$ fertilizer in flue cured tobacco and incidence of tobacco vein spot disease was analyzed. The final result confirmed that nitrogen fertilizer became the biggest effect to the morbidity of the plant under the same experimental conditions, which should be paid attention to in practice.
\end{abstract}

\section{Introduction}

Tobacco vein spot disease is prevalent in the world. It is also known as tobacco potato $\mathrm{Y}$ virus disease, which badly hurt tobacco production, the loss is very obvious. In 1989, tobacco vein spot disease outbroke in Canada, causing direct economic losses of more than one million dollars, the yield of tobacco in Italy has been directly reduced by 35\%. In China, Heilongjiang, Anhui, Yunnan, Henan, Shandong and some other regions have also been seriously affected, the distribution range of which is very wide. Since effective control hasn' $t$ been done to this disease so far, its damage has affected tobacco fungal diseases. As the plants do not have immune system similar to vertebrates, virus remains infected during the whole growth and development after invading the plants. Once the condition permits, it will result in the outbreak. For tobacco vein spot diseases, "prevention first, comprehensive treatment" should be the main intervention principle. Exploring effective prevention strategies has very important practical significance. In this paper, we explore and analyse the correlation between different levels and ratios of $\mathrm{N}, \mathrm{P}, \mathrm{K}$ fertilizer in the same conditions and the incidence of tobacco vein spot disease.

\section{Materials and methods}

General information. This article chooses Zhenhong Road 14, North gate, Zhaoyang District, Zhaotong City, Yunnan Province. Soil properties are yellow, fertility is in the upper middle. The terrain is relatively flat, not paddy field and dry land. The variety of tobacco is Yunyan 87. The fertilizer is a compound fertilizer for tobacco use, the ratio of N, P and $\mathrm{K}$ is 10:14:24, and introduction, in addition to $16 \%$ calcium superphosphate and $50 \%$ potassium sulfate compound fertilizer.

Experiment. The use of pure $\mathrm{N}$ fertilizer in planting field per acre is $4 \mathrm{~kg}, 6 \mathrm{~kg}$ and $8 \mathrm{~kg}$ respectively, the level of $\mathrm{P}$ and $\mathrm{K}$ fertilizer applies positive value design. The ratio of $\mathrm{N}$ fertilizer and superphosphate is $1: 1,1: 1.5$ and $1: 2$; the ratio of $\mathrm{N}$ fertilizes and potassium sulfate compound fertilizer is 1:2, 1:2.5 and 1:3 respectively. Different fertilization amount and proportion form 9 combinations, repeating 3 times with random test. The area of each district is 25 square meters; there are protective measures around the district. Make sure that the use of the fertilizer is completely organic fertilizer, and then take the way of Tong Shi before transplanting, according to the actual amount of different districts. 
Table1. Experimental design and treatment of the quantity and proportion of fertilizer

\begin{tabular}{ccccc}
\hline number & The ratio of N, P, K & N fertilizer(kg/ acre) & P fertilizer(kg/ acre) & K fertilizer(kg/ acre) \\
\hline 1 & $1: 1: 2$ & 4 & 4 & 8 \\
\hline 2 & $1: 1.5: 2.5$ & 4 & 6 & 10 \\
\hline 3 & $1: 2: 3$ & 4 & 8 & 12 \\
\hline 4 & $1: 1: 2.5$ & 6 & 6 & 15 \\
\hline 5 & $1: 1.5: 3$ & 6 & 9 & 18 \\
\hline 6 & $1: 2: 2$ & 6 & 12 & 12 \\
\hline 7 & $1: 1: 3$ & 8 & 8 & 24 \\
\hline 8 & $1: 1.5: 2$ & 8 & 12 & 16 \\
\hline
\end{tabular}

Management method. Experimental treatment and transplant are done to all the plants on May 22, 2014. The management of experimental conformed to normalized technical measures of flue cured tobacco in Zhaotong City, floating seedling was applied to. Pesticides were not sprayed in the field. We dealt with weeds in a certain period of time in the district.

Application of survey method of fixed point and time, we investigated all flue cured tobacco in 3 repeated test plots at one time, the number of infected plants and disease progression were observed and recorded in detail, the actual incidence and disease index were calculated. In this study, we found infected plants on July 2nd after transplanting on May 22nd 2014, and then began to carry out the investigation of disease progression, investigated the amount of the infected plants every 10 days.

Classification and evaluation method of disease severity and disease. In this experiment, the classification of the severity of the disease and the calculation method of the disease of flue cured tobacco is strictly in accordance with $<$ Survey method of the tobacco plant diseases classification $>$ to evaluate the disease severity classification.

Actual incidence $=($ injected plants amount/total amount $) * 100 \%$

Tobacco leaf spot index $=\sum[$ ( disease progression $\cdot$ number of plants in this class)/ (number of the highest incidence $\bullet$ number of plants investigated ) ]

The tobacco disease progression was Level 0: no sign of diseases in the whole plant of flue cured tobacco; Level 1: the disease of the whole plant was slight, only a few spots appeared; The diameter of the scab was in $2 \mathrm{~mm}$ and number of total spots was in 15 , the number of the spots whose diameter was more than 2mm was not more than 2; Level 3: the whole leaves of flue cured tobacco had a small amount of spots, the number of the small spots whose diameter was in $2 \mathrm{~mm}$ was below 50, the number of the big spots was between 2-10; Level 5: the whole plant of flue-cured tobacco had spots more than one third to two thirds ,the number of small diameter below $2 \mathrm{~mm}$ was more than 50 , but less than 100, the number of big spots was between 10-20. Level 7: one third of the leaves showed moderate to multiple quantity of spots, the number of small spots was more than 100 , the big spots was more than 20, the lower part of the plant exhibited a phenomenon of the emergence of perish of individual leaves; Level 9: more than 2/3 of the leaves had a large number of big spots, many leaves died away.

\section{Results}

According to the results of the experiment, Number 1,2,3,7,8,9 had very significant differences of the incidence of disease, and Number9 is the most significant. So we can learn that with the amount of $\mathrm{N}$ fertilizer increasing, the incidence of the disease is gradually decreasing. Since the incidence of No.9 was the lowest, much lower than No.1, we can know that the optimal mix ratio of N, P and N fertilizer was No.9, that is the amount of pure nitrogen fertilizer per acre is $8 \mathrm{~kg}$, the ratio of $\mathrm{N}, \mathrm{P}$ and $\mathrm{K}$ is $1: 2: 2.5$. 
Table 2. Statistics on the incidence of the flue cured tobacco vein spot disease

\begin{tabular}{cccccc}
\hline number & I & II & III & total & average \\
\hline 1 & 31.21 & 28.64 & 25.90 & 85.75 & 28.58 \\
\hline 2 & 29.55 & 27.03 & 26.12 & 82.70 & 27.57 \\
\hline 3 & 32.00 & 23.15 & 28.05 & 83.20 & 27.73 \\
\hline 4 & 20.21 & 26.64 & 23.30 & 80.15 & 26.72 \\
\hline 5 & 26.59 & 21.29 & 26.04 & 73.92 & 24.64 \\
\hline 6 & 28.26 & 20.10 & 26.75 & 75.11 & 25.04 \\
\hline 7 & 20.23 & 19.55 & 23.45 & 63.23 & 21.08 \\
\hline 8 & 25.60 & 21.40 & 19.92 & 66.92 & 23.91 \\
\hline 9 & 21.65 & 17.32 & 22.04 & 60.99 & 20.33 \\
\hline
\end{tabular}

Table 3. Analysis on the incidence of tobacco vein spot disease

\begin{tabular}{cccccc}
\hline Source of variation & Degrees of freedom & Sum of Squares & mean square & F value & Significant level \\
\hline Between treatments & 2 & 67.9254 & 33.9627 & 18.742 & 0.0088 \\
\hline between blocks & 2 & 17.9822 & 8.9911 & 5.1136 & 0.0790 \\
\hline error & 4 & 7.0331 & 1.7583 & & \\
\hline Total variation & 8 & 92.9407 & & & \\
\hline
\end{tabular}

To deal with the effects of nitrogen fertilizer and tobacco vein spot disease incidence rate, we can get the effect of the incidence of different fertilizers. $\mathrm{N}$ has the greatest impact on the plant disease, in comparison, the effect of $\mathrm{P}$ and $\mathrm{K}$ fertilizer is not obvious. Especially in the case of $4 \mathrm{~kg}$ or $8 \mathrm{~kg}$ pure $\mathrm{N}$ fertilizer per acre, differences of the incidence of tobacco vein spot disease was significant ( $\mathrm{F}$ value=18.742); $4 \mathrm{~kg}$ 、 $6 \mathrm{~kg}$ and $8 \mathrm{~kg} \mathrm{~N}$ fertilizer per acre are the same.

We can find from the analysis of tobacco vein spot disease index that the difference of No.1,2,7 and 8 is very significant, and No.1,2,3 and No.4,7,8 are the same. The disease index of No.5 is the lowest, compared to the highest No.1, the difference is significant. Results suggest that the lowest disease index is No.5, which the pure $\mathrm{N}$ fertilizer per acre is $6 \mathrm{~kg}$, the ratio of $\mathrm{N} 、 \mathrm{P} 、 \mathrm{~K}$ is set to $1: 1.5: 3$.

Table 4. Statistics on the incidence of the flue cured tobacco vein spot disease

\begin{tabular}{cccccc}
\hline number & I & II & III & total & average \\
\hline 1 & 17.25 & 9.30 & 8.45 & 35.00 & 11.67 \\
2 & 19.00 & 12.47 & 7.50 & 38.97 & 12.99 \\
3 & 16.25 & 11.35 & 8.21 & 35.81 & 11.94 \\
4 & 13.35 & 8.35 & 6.23 & 27.93 & 9.31 \\
5 & 8.46 & 8.05 & 6.24 & 20.75 & 6.17 \\
6 & 9.45 & 8.90 & 7.50 & 25.85 & 8.58 \\
7 & 11.44 & 10.26 & 8.20 & 29.90 & 9.97 \\
8 & 11.20 & 6.35 & 7.25 & 24.80 & 8.27 \\
9 & 20.12 & 8.58 & 7.46 & 36.12 & 12.04 \\
\hline
\end{tabular}

\section{Conclusion}

Tobacco vein spot disease is one of the main culprits in the world tobacco production. As time goes on, tobacco vein spot disease has become increasingly important for tobacco growing, and has become the main virus species of tobacco in Yunnan, Henan, Shandong and other provinces of China. Due to the differences in ecological environment, tobacco cultivars and the occurrence regularity of the aphids of vein spot virus, resulting in great differences between the occurrence regularity and control methods of the vein spot disease, lacking of effective prevention technology.

According to relevant report, the occurrence and development of tobacco vein spot disease is closely related to the nightshade such as potato and the presence of winged aphids. It is suggested that the closer the tobacco growing and potato crops are, and the possibility of the occurrence of vein spot disease is higher. In addition, the emergence of the disease has relationship with tobacco varieties, transplanting methods, breeding methods, fertilization, etc. It is reported that the peak occurres in tobacco vein disease when aphids in field enter the peak of flight around 10 days, especially after 
China's warm winter, the temperature rises, the cardinality of the aphids overwinter is very large, there is a high chance to appear aphids, which is the main reason that aphid transmitting vein spot disease. Virus infection can be reduced by preventing aphids and cutting off the transmission route. Some studies suggested that using silver gray film and 40 fly net to control aphids in seedbed period, using silver gray film covering during field period. During the peak of aphid invasion, you can choose Pirimicarb, dimethoate and other conventional drugs to kill them. In the process of spray, attention should be paid to the location where a large number of aphids such as the back of the leaves, tender leaf, bud, etc. In the process of selecting anti-insect drugs, you should focus on the choice of drugs that do no harm to aphid enemies, such as chrysopids, ladybug etc.

In general, the suitable temperature of tobacco vein spot disease virus is $20-30^{\circ} \mathrm{C}$, Excessive temperature may cause symptoms or the phenomenon of symptoms is not obvious, and the fall of temperature will lead to symptoms reoccurrence. If it rains or someone water in the environment of temperature above $25^{\circ} \mathrm{C}$, the small climate changes in the field, the resistance of the plant will be decreased, and the symptoms of the plant will be aggravation, so will the tobacco grow in the shade or in a low position or on the sunny side. High winds can increase the friction between tobacco and tobacco leaves, resulting in a large number of virus spread in the field. At the same time, soil hardens in the field and poor air permeability will also increase the severity of the illness. At present, the main strategies to tobacco vein spot disease in China are cultivation management, prevention and control of aphids, application of antiviral agents and gene engineering, etc. According to the relevant data, in the process of tobacco planting, balanced nutrition and reasonable fertilizer can effectively improve the state of an illness.

By improving the amount of $\mathrm{K}$ fertilizer and organic fertilizer can improve the tobacco nutrition resistance, enhance the ability of antiviral. In addition, it is reported that the iodine element has a good effect on tobacco virus activity, it can greatly reduce the virus activity when the soil $\mathrm{pH}$ value is higher or lower than 5.5-6.0. Besides, it is important to note that the incidence of vein spot disease is not only related to fertilization factors, but also closely related to the climate, environment, transplanting process, aphids and some other factors. Research shows some measures such as strengthening field management and seedbed can reduce the virus infection rate. Tobacco planting fields should not be near the fields that plant solanaceae plants like potato and cucurbitaceae plants, and all the more so at seedling stage, the use of no manure composting should be avoided during planting period. In addition, although tobacco seeds do not carry virus, impurities, dirt and other impurities that are mixed in the surface of the seeds may contain viruses. So it is very important to disinfect the seeds, disinfectant treatment can be done to the seeds after antiviral agents being diluted routinely.

In this study, the effect of the factors such as different amount and ratio of fertilizer of tobacco to the incidence rate of the plant and disease index were analyzed. It was found that the largest effect on the incidence of the plant was made by $\mathrm{N}$ fertilizer, while the effect of $\mathrm{P}$ and $\mathrm{K}$ fertilizer on the incidence of the disease was small. Especially in the planting fields where $4 \mathrm{~kg}$ and $8 \mathrm{~kg}$ of $\mathrm{N}$ fertilizer were applied per acre, the differences between the rate of the disease was very significant. With the increase of fertilization amount, the incidence rate of tobacco vein spot diseases showed a declining trend, district No. 9 showed the lowest. The optimal mix ratio of N、P、K fertilizer per acre planting fields was $8 \mathrm{~kg}$ of pure nitrogen, the ratio of $\mathrm{N} 、 \mathrm{P} 、 \mathrm{~K}$ was $1: 2: 2.5$. The effects of the three factors and ratio of $\mathrm{N}, \mathrm{P}$ and $\mathrm{K}$ fertilizer on tobacco vein spot disease was analyzed, we found that the effect of $\mathrm{N}$, $\mathrm{P}$ and $\mathrm{K}$ on the disease was not very obvious, among which, the disease index of No. 5 was the lowest, and the disease index of No.2 was the highest. That is $6 \mathrm{~kg}$ pure $\mathrm{N}$ fertilizer was applied per acre planting fields, the proportion of $\mathrm{N}, \mathrm{P}$ and $\mathrm{K}$ elements was 1:1.5:3. We can know that reasonable fertilization program can largely reduce the occurrence and development of vein spot diseases, narrow the harm scope vein spot diseases do to the tobacco plants, which has a very high application value, and can provide references for future tobacco planting. 


\section{Acknowledgments}

This paper is the subject of Education Department of Yunnan province. subject name: Research of correlation between the incidence of tobacco vein spot disease and the amount of fertilizer application. Subject number: 2012C208.

\section{References}

[1] Liangbo Cao, Yingxia Guang. Research of the correlation between the incidence of tobacco vein spot disease and the amount of fertilizer application. Southern agriculture, 2012,06(3):16-18.

[2] Conglu Li, Tanggui You, Wei Huang. Screening of high efficiency and low toxicity pesticides to control tobacco vein spot disease media myzus persicae. Agricultural Sciences of Anhui. 2013,41(1):128,132.

[3] Shikai Tang, Lifang Liu, Yongmei Li. The effect of tobacco intercropping with sweet potato on the control of tobacco diseases. Agricultural Sciences of Guangdong, 2008,(9):26-28.

[4] Yingxia Guang, Liangbo Cao. Primary study on the prevention and control of flue cured tobacco vein spot disease of microbial agent. Journal of Kunming University, 2012,(3):11-12.

[5] Yongping Li, Bingguang Xiao, Fangchan Jiao. The selection of new variety of flue cured tobacco Yunyan 97 and its characteristics. Science of Chinese tobacco. 2012,(4):28-31. 